\title{
Adaptasi Employee Well-Being Scale (EWBS) Versi Bahasa Indonesia
}

\author{
Tuti Rahmi' ${ }^{12}$,Hendriati Agustiani' ${ }^{1}$, Diana Harding ${ }^{1}$, Efi Fitriana ${ }^{1}$ \\ ${ }^{1}$ Fakultas Psikologi Universitas Padjadjaran \\ ${ }^{2}$ Fakultas Psikologi dan Kesehatan Universitas Negeri Padang \\ email: tuti.rahmi@fip.unp.ac.id
}

\section{Artikel INFO}

Diterima:14 Juni 2021

Direvisi: 28 Juli 2021

Disetujui: 03 Agustus 2021

DOI:

http://dx.doi.org/10.24014/ jp.v14i2.13112

\section{Abstrak}

Penelitian ini bertujuan untuk mengadaptasi Employee Well-Being Scale (EWBS) ke dalam versi Bahasa Indonesia. Penelitian menggunakan pendekatan kuantitatif dengan metode survey. Terdapat 201 orang karyawan dari salah satu perusahaan perkebunan di Indonesia yang mengisi skala penelitian ini. Validitas konstrak dilakukan dengan confirmatory factor analysis dengan menggunakan lisrel 8.8. Validitas konvergen diuji dengan mengkorelasikan EWBS dengan Utrecht Work Engagement Scale (UWES), sedangkan validitas diskriminan diuji dengan mengkorelasikan EWBS dengan Perceived Stress Scale (PSS). Reliabilitas alat ukur menggunakan nilai CR (Constract Reliability). Hasil confirmatory factor analysis menunjukkan bahwa model pengukuran fit dengan data. Begitu juga dengan reliabilitas dari alat ukur ini. Employee well-being berhubungan positif dengan work engagement sebaliknya berhubungan negatif dengan perceived stress. Berdasarkan hal tersebut dapat dikatakan bahwa EWBS memiliki validitas dan reliabilitas yang cukup baik dan dapat digunakan di Indonesia.

Kata Kunci: Employee Well-Being Scale, Adaptasi, Validasi

\section{Adaptation of Employee Well-Being Scale (EWBS) of Indonesian Version}

\begin{abstract}
This study aimed to adapt the Employee Well-Being Scale (EWBS) into the Indonesian version. This research used a quantitative approach with a survey method. There were 201 employees from one of a plantation company in Indonesia who filled the scale of the study. Construct validity was tested by confirmatory factor analysis using Lisrel 8.8. Convergent validity was tested by correlating the EWBS with the Utrecht Work Engagement Scale (UWES), while discriminant validity was tested by correlating the EWBS with the Perceived Stress Scale (PSS). The reliability of the scale used CR (Constract Realibility) values. The confirmatory factor analysis results showed that the measurement model fits the data best. CR value was accepted. Employee well-bing was positively related to work engagement and negatively associated with perceived stress. The study's finding indicated that EWBS had good psychometric properties and provided supportive evidence for use in the Indonesian context.
\end{abstract}

Keywords: Employee Well-Being Scale, Adaptation, Validation

\section{Pendahuluan}

Well-being adalah hal yang diimpikan oleh banyak orang. Tidak ada orang yang tidak ingin merasakan well-being dalam hidupnya. Banyak yang rela melakukan apapun untuk merasakan well-being. Wellbeing menurut Brey (2012) secara tradisional menjadi topik studi filosofis, tetapi dalam beberapa dekade terakhir menjadi perhatian penting di bidang lain, terutama Psikologi dan Ekonomi. Penelitian empiris pada well-being dan happiness menjadi sangat berpengaruh pada kebijakan yang dibuat, di mana pengukurannya semakin banyak digunakan untuk menjadi dasar kebijakan sosial dan ekonomi.

Tidak hanya dalam kehidupan secara umum, secara khusus well-being juga dibutuhkan di tempat kerja. Beberapa istilah yang digunakan misalnya work related well-being atau employee well-being, sebagian peneliti tetap menggunakan psychological wellbeing dan subjective well-being walaupun penelitian tersebut dilakukan pada setting 
kerja, beberapa penelitian tersebut adalah oleh Ariza-Montes et al. (2018), Kun et al., (2016), Dagenais-Desmarais \& Savoie (2012) dan Shier \& Graham (2011). Disamping itu sebuah systematic review juga menyatakan bahwa perlunya pengembangan teori, penelitian, dan praktik mengenai kesehatan dan well-being dari perspektif organisasi (Danna, 1999). Di sisi lain, banyak penelitian yang dilakukan tentang employee well-being yang menggunakan kepuasan kerja sebagai pengukurannya (Dimotakis et al., 2011), sikap kerja (Leavitt et al., 2011) negative affect (Vandenberghe et al., 2011) atau flow (Ceja \& Navarro, 2011).

Sejumlah pengukuran dengan konteks dan model yang spesifik banyak dikembangkan untuk meneliti well-being di lingkungan pekerjaan. Dari segi sejarah, banyak peneliti mengukur kepuasan kerja karyawan, baik secara global atau sebagai penjumlahan dari kepuasan dengan berbagai domain pekerjaan (Spector, 1997). Peneliti lain (T. A. Wright \& Cropanzano, 1997) telah mengkritik operasionalisasi yang tidak memadai tentang well-being di tempat kerja. Beberapa peneliti telah menyarankan menggunakan ukuran-ukuran pengaruh disposisi (Wright \& Cropanzano, 2004) atau employees' work-related affect (Daniels, 2000) untuk mengganti pengukuran kepuasan kerja. Dalam beberapa tahun terakhir, para peneliti telah menggunakan pendekatan multi pengukuran. Cotton \& Hart (2003) misalnya, mengoperasionalisasikanemployee well-being terdiri dari positive affect dan negative affect dan evaluasi kognitif dari job satisfaction. Peneliti lain juga menyarankan bahwa employee well-being harus dipandang mencakup pengalaman psikologis dan status kesehatan yang terkait dengan pekerjaan dan yang tidak terkait dengan pekerjaan (Page \& Vella-Brodrick, 2009).

Page \& Vella-Brodrick (2009) menyarankan model untuk menambahkan kepuasan kerja, yang melengkapi langkah-langkah subjective well-being dalam mengembangkan model employee well-being, bersama-sama, kepuasan kerja dan work-related affect dapat merupakan suatu employee's workplace well-being (workplace well-being). Pada model ini, employee well-being terdiri dari tiga komponen dasar: subjective well-being, workplace well-being, dan psychological well-being. Subjective well-being terdiri dari kepuasan hidup dan dispositional affect, sedangkan workplace well-being meliputi kepuasan kerja dan work-related affect. Baik dispositional affect dan work-related affect terdiri dari komponen positif dan negatif. Psychological well-being terdiri dari enam dimensi: self acceptance, hubungan yang positif dengan yang lain, environmental mastery, otonomi, pengembangan diri, dan tujuan dalam hidup (Page \& Vella-Brodrick, 2009).

Didasari oleh konsep yang dikemukakan oleh Page \& Vella-Brodrick (2009), Zheng et al. (2015) mengembangkan konsep employee well-being dengan melakukan delapan studi, yang dimulai dengan melakukan riset secara kualitatif, hingga melakukan penelitian crosscultural untuk memastikan bahwa konsep ini dapat digunakan pada budaya barat dan timur. Zheng et al. (2015) mengemukakan bahwa employee well-being terdiri dari tiga dimensi, yaitu life-well being, workplace wellbeing dan psychological well-being. Aspek life-well being mencakup perawatan pribadi dan keluarga (mencerminkan emosi pribadi karyawan) dan anggota keluarga (masalah kehidupan keluarga). Aspek workplace wellbeing meliputi elemen terkait pekerjaan, seperti kompensasi dan tunjangan, perlindungan tenaga kerja, layanan logistik, gaya manajemen, dan pengaturan kerja. Aspek psychological well-being terutama berfokus pada pembelajaran, pertumbuhan, prestasi kerja, dan aktualisasi diri.

Hasil penelitian menunjukkan bahwa kinerja yang optimal dapat diprediksi oleh well-being (Cotton \& Hart, 2003). Sehingga 
employee well-being sangat penting untuk kelangsungan hidup dan perkembangan organisasi, sementara hingga saat ini belum ada penelitian yang melakukan adaptasi alat ukur ini dalam versi bahasa Indonesia. Oleh karena itu, sangat penting untuk diteliti lebih lanjut di Indonesia yang membutuhkan alat ukur yang valid dan realiabel dengan melakukan adapatasi alat ukur EWBS yang dikembangkan oleh Zheng et al. (2015). Berdasarkan penjelasan sebelumnya maka tujuan penelitian ini adalah mengadaptasi Employee Well-being Scale dalam versi bahasa Indonesia.

\section{Metode}

Validasi alat ukur diawali dengan permintaan izin melalui email oleh peneliti kepada pemilik alat ukur aslinya yaitu Zheng et al. (2015). Setelah mendapatkan izin, kemudian dilakukan penterjemahan secara forward dan backward translation. Hasil terjemahan didiskusikan dengan lima orang tim ahli Psikologi dan Manajemen yang memiliki kemampuan Bahasa Inggris yang baik. Setelah itu dilakukan uji keterbacaan dengan pilot study kepada sepuluh orang responden. Beberapa item mengalami beberapa penyesuaian setelah pilot study. Kemudian setelah semua item dianggap baik dilakukan uji coba di lapangan.

\section{Partisipan}

Penelitian ini menggunakan pendekatan kuantitatif dengan metode survey. Penelitian dilakukan di salah satu perusahaan perkebunan di Indonesia. Jumlah responden yang mengisi skala penelitian adalah 201 orang dengan kriteria telah menjadi karyawan tetap minimal selama dua tahun. Penyebaran skala alat ukur dilakukan secara online yang juga memuat informed consent, sebelumnya penelitian ini juga telah dinyatakan layak dan telah memiliki ethical clearance yang terdaftar pada Komite Etik Universitas Padjadjaran
No. 378/UN6.KEP/EC/2020. Link alat ukur penelitian diserahkan kepada Divisi Sumber Daya Manusia perusahaan untuk disebarkan kepada para karyawan yang memenuhi syarat untuk mengisi angket tersebut.

\section{Pengukuran}

Alat ukur yang disebarkan secara online tidak hanya memuat EWBS namun juga memuat alat ukur yang nantinya digunakan sebagai convergent validity yaitu dengan menggunakan skala Utterch Work Engagement Scale (UWES) dan Percieved Stress Scale (PSS) untuk discriminant validity yang telah diadaptasi dalam versi bahasa Indonesia. Work Engagement dipilih sebagai convergent validity karena dari hasil penelitian sebelumnya berhubungan positif dengan well-being (Ariza-Montes et al., 2019; Garg \& Singh, 2019; Joo \& Lee, 2017), di sisi lain sebagai discriminant validity well-being berhubungan negatif dengan stress (Mlangeni \& Van Dyk, 2017; Rahmi et al., 2021).

Work engagement diukur dengan menggunakan versi Bahasa Indonesia dari Utrecht Work Engagement Scale (UWES) versi pendek yaitu sembilan item. Skoring pada UWES bergerak dari 1-5 dengan pilihan jawaban tidak pernah hingga selalu. UWES versi Bahasa Indonesia diadaptasi dan divalidasi oleh Rahmadani, Schaufeli, Ivanova, \& Osin (2019). Sedangkan Perceived Stress diukur dengan Perceived Stress Scale dari Cohen (1986) yang telah diterjemahkan sebelumnya oleh Saraswati (2017), dengan jumlah 10 item, rentang skor 1-5 dengan pilihan jawaban dari tidak pernah hingga sangat sering. Sedangkan EWSS sendiri memiliki 18 item dengan skor 1-7 dan pilihan jawaban dari sangat setuju hingga sangat tidak setuju (Zheng et al., 2015).

\section{Analisis Data}

Analisis Data dilakukan dengan confirmatory factor analysis untuk menganalisis validitas konstrak untuk mengkonfirmasi model 
pengukuran yang diajukan oleh Zheng et al. (2015). Analisis data menggunakan lisrel 8.8. Sedangkan untuk reliabilitas menggunakan nilai $C R$ (construct realiability). Convergent validity diuji dengan mengkorelasikan EWBS dengan UWES sedangkan discriminant validity diuji dengan mengkorelasikan EWBS dengan PSS menggunakan SPSS versi 25.

\section{Hasil}

Hasil analisis menggunakan Lisrel 8.80 menunjukkan nilai-nilai goodness of fit, yaitu Chi-Square $=252.30, d f=132, p$-value $=0.00$ dan
RMSEA=0.096 yang menunjukan hasil yang tidak fit. Setelah dilakukan modifikasi dengan mengkorelasikan measurement error (Bollen, 2014; Jöreskog, 1970) maka didapatkan ChiSquare $=135.81, d f=118, p$-value $=0.12538$ dan $R M S E A=0.039$ yang menunjukkan model telah fit. Berdasarkan Tabel 1 juga dapat nilainilai Goodness of fit yang diperoleh dari hasil output yang menunjukkan standar-standar yang diharapkan dapat tercapai dengan cukup baik.

Tabel 1. Goodness of Fit Uji Model EWBS

\begin{tabular}{lll}
\hline \multicolumn{1}{c}{ Ukuran GOF } & \multicolumn{1}{c}{ Target Kecocokan } & Keterangan \\
\hline $\mathrm{NFI}=0.96$ & $\geq 0.90$ & Good Fit \\
$\mathrm{CFI}=0.98$ & $\geq 0.90$ & Good Fit \\
Standardized RMR $=0.058$ & $\leq 0.10$ & Good Fit \\
$\mathrm{AGFI}=0.90$ & $0.80 \leq \mathrm{AGFI}<0.90$ & Good Fit \\
\hline
\end{tabular}

Sumber: Output Lisrel 8.8 (2021)

Tabel 2 menunjukkan loading factor setiap yang signifikan $(T>1.96)$. Selain itu $C R$ item. Berdasarkan Gambar 1 juga dapat dilihat (Construct Reliability) yang diperoleh pada model pengukuran dari EWBS berdasarkan penelitian ini adalah 0.942.

nilai $T$ value yang telah menunjukkan item

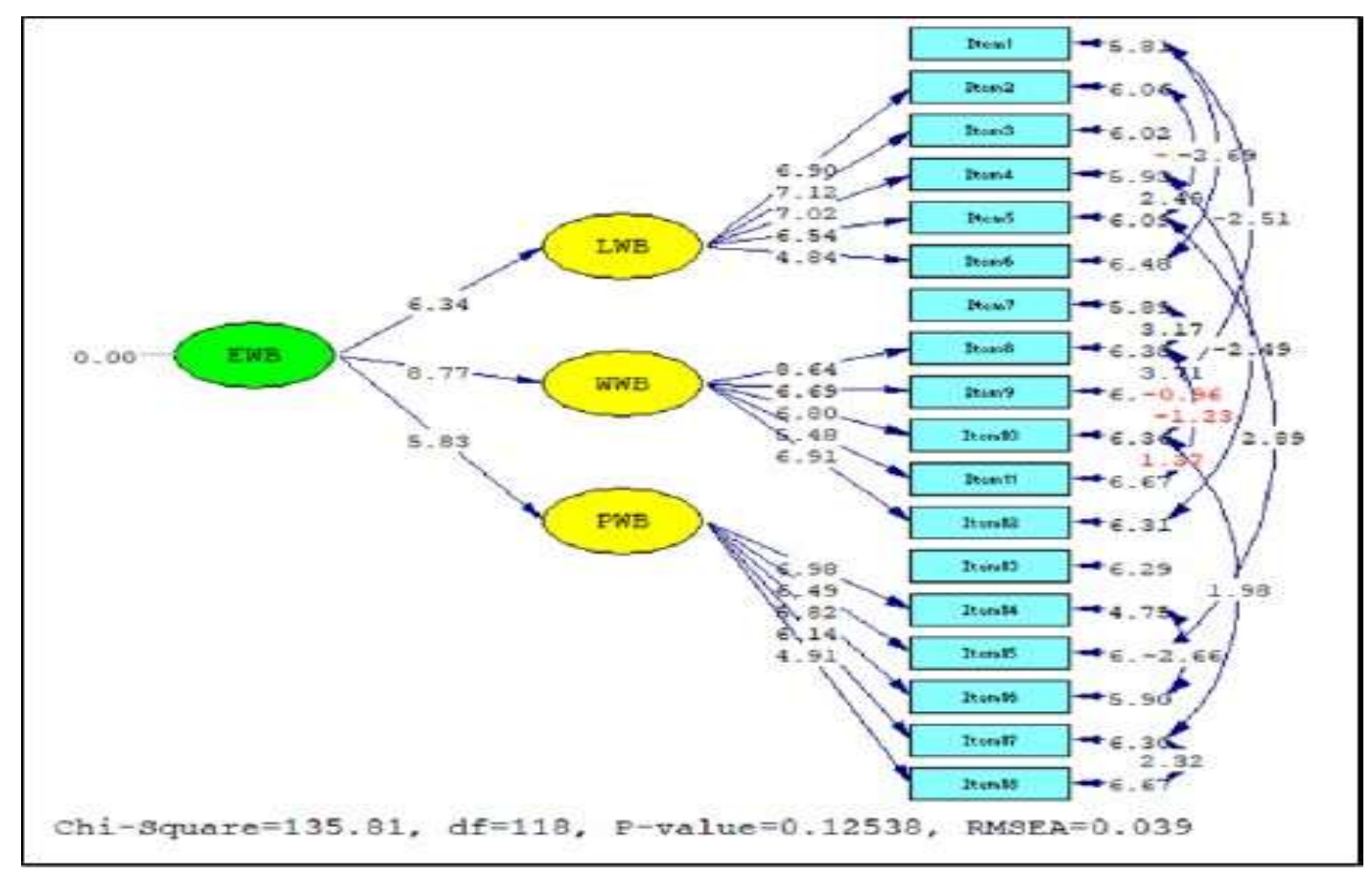

Gambar 1. Model Uni Dimensi berdasarkan $T$ Value yang fit dengan data dengan Sembilan korelasi antar measurement error 
Dari Gambar 1 dapat dilihat setiap item dengan loading factor-nya. Misalnya pada dimensi Life Well-Being pada item pertama (saya merasa puas dengan hidup saya) menunjukkan loading factor sebesar 0.74 . Pada dimensi Workplace Well-Being pada item ke-tujuh (saya puas pada tugas yang menjadi tanggung jawab saya) menunjukkan loading factor sebesar 0.76. Begitu juga pada dimensi psychological well-being pada item ketiga belas (Saya merasa telah berkembang menjadi manusia yang lebih baik) menunjukkan factor loading yang juga memuaskan yaitu 0.68 .

Tabel 2. Koefisien Muatan Faktor

\begin{tabular}{|c|c|c|}
\hline Dimensi & Item & $\begin{array}{l}\text { Loading } \\
\text { Factor }\end{array}$ \\
\hline \multirow{6}{*}{$\begin{array}{l}\text { Life Well- } \\
\text { Being }\end{array}$} & Saya merasa puas dengan hidup saya. & 0.74 \\
\hline & $\begin{array}{l}\text { Saya sudah mendekati impian saya dalam sebagian besar aspek } \\
\text { kehidupan saya. }\end{array}$ & 0.72 \\
\hline & $\begin{array}{l}\text { Saya merasakan kebahagiaan yang sebenarnya hampir sepanjang } \\
\text { waktu }\end{array}$ & 0.74 \\
\hline & Saya berada di situasi kehidupan yang baik & 0.74 \\
\hline & Hidup saya sangat menyenangkan. & 0.69 \\
\hline & $\begin{array}{l}\text { Cara hidup saya saat ini sudah sesuai untuk mempersiapkan } \\
\text { kehidupan di akhirat }\end{array}$ & 0.58 \\
\hline \multirow{6}{*}{$\begin{array}{l}\text { Workplace } \\
\text { Well-Being }\end{array}$} & Saya puas dengan tugas yang menjadi tanggung jawab saya & 0.76 \\
\hline & $\begin{array}{l}\text { Secara umum, saya merasa cukup puas dengan pekerjaan saya saat } \\
\text { ini. }\end{array}$ & 0.70 \\
\hline & Saya benar-benar menikmati pekerjaan saya. & 0.67 \\
\hline & $\begin{array}{l}\text { Saya selalu dapat menemukan cara untuk meningkatkan kualitas } \\
\text { pekerjaan saya. }\end{array}$ & 0.68 \\
\hline & Bekerja merupakan pengalaman yang berarti bagi saya. & 0.56 \\
\hline & $\begin{array}{l}\text { Pada dasarnya saya merasa puas dengan pencapaian saya pada } \\
\text { pekerjaan saya saat ini. }\end{array}$ & 0.69 \\
\hline \multirow{6}{*}{$\begin{array}{l}\text { Psychological } \\
\text { Well-Being }\end{array}$} & Saya merasa telah berkembang menjadi manusia yang lebih baik & 0.68 \\
\hline & Saya menyelesaikan urusan sehari-hari dengan baik. & 0.82 \\
\hline & $\begin{array}{l}\text { Secara umum, saya merasa nyaman dengan diri saya sendiri, dan } \\
\text { saya percaya diri. }\end{array}$ & 0.72 \\
\hline & $\begin{array}{l}\text { Orang lain menganggap saya sebagai seseorang yang bersedia } \\
\text { memberikan dan meluangkan waktu saya untuk orang lain. }\end{array}$ & 0.67 \\
\hline & Saya mampu membuat jadwal yang fleksibel untuk pekerjaan saya. & 0.68 \\
\hline & $\begin{array}{l}\text { Saya senang terlibat dalam pembicaraan yang mendalam dengan } \\
\text { keluarga dan teman-teman saya, sehingga kami lebih saling } \\
\text { memahami }\end{array}$ & 0.54 \\
\hline
\end{tabular}

Penelitian ini juga berusaha membuktikan validitas konvergen dan validitas diskriminan. Berdasarkan hasil analisis terlihat bahwa validtas konvergen terbukti yang menunjukkan bahwa well-being berhubungan positif dengan work engagement serta berhubungan negatif dengan perceiced stress. Korelasi skor total dan dimensi setiap konstrak dapat dilihat pada Tabel 3. 
Tabel 3. Interkorelasi, Validitas Konvergen and Validitas Diskriminan EWBS

\begin{tabular}{|c|c|c|c|c|c|c|c|c|c|c|c|c|}
\hline & $\begin{array}{l}\text { Variabel dan } \\
\text { Dimensinya }\end{array}$ & 1 & 2 & 3 & 4 & 5 & 6 & 7 & 8 & 9 & 10 & 11 \\
\hline 1 & $\begin{array}{l}\text { Employee Well- } \\
\text { Being }\end{array}$ & & & & & & & & & & & \\
\hline 2 & Life Well-Being & $.858^{* *}$ & & & & & & & & & & \\
\hline 3 & $\begin{array}{l}\text { Work Place } \\
\text { Well-Being }\end{array}$ & $.921^{* *}$ & $.717^{* *}$ & & & & & & & & & \\
\hline 4 & $\begin{array}{l}\text { Psychological } \\
\text { Well-Being }\end{array}$ & $.849^{* *}$ & $.533^{* *}$ & $.703^{* *}$ & & & & & & & & \\
\hline 5 & $\begin{array}{l}\text { Work } \\
\text { Engagement }\end{array}$ & $.513^{* *}$ & $.318^{* *}$ & $.533^{* *}$ & $.499^{* *}$ & & & & & & & \\
\hline 6 & Vigor & $.503^{* *}$ & $.328^{* *}$ & $.506^{* *}$ & $.489^{* *}$ & $.918^{* *}$ & & & & & & \\
\hline 7 & Dedication & $.472^{* *}$ & $.294^{* *}$ & $.510^{* *}$ & $.438^{* *}$ & $.923^{* *}$ & $.817^{* *}$ & & & & & \\
\hline 8 & Absorption & $.412^{* *}$ & $.238^{* *}$ & $.424^{* *}$ & $.423^{* *}$ & $.863^{* *}$ & $.664^{* *}$ & $.674^{* *}$ & & & & \\
\hline 9 & $\begin{array}{l}\text { Perceived } \\
\text { Stress }\end{array}$ & $-.331^{* *}$ & $-.219^{* *}$ & $-.312^{* *}$ & $-.339^{* *}$ & $-.420^{* *}$ & $-.459^{* *}$ & $-.417^{*}$ & $-.258^{* *}$ & & & \\
\hline 10 & $\begin{array}{l}\text { Perceived } \\
\text { Helplesness }\end{array}$ & $-.331^{* *}$ & $-.217^{* *}$ & $-.332^{* *}$ & $-.323^{* *}$ & $-.412^{* *}$ & $-.445^{* *}$ & $-.414^{* *}$ & $-.252^{* *}$ & $.947^{* *}$ & & \\
\hline 11 & $\begin{array}{l}\text { Perceived } \\
\text { inefficacy }\end{array}$ & $-.300^{* *}$ & $-.200^{* *}$ & $-.266^{* *}$ & $-.323^{* *}$ & $-.390^{* *}$ & $-.430^{* *}$ & $-.382^{* *}$ & $-.240^{* *}$ & $.957^{* *}$ & $.813^{* *}$ & \\
\hline
\end{tabular}

Berdasarkan Tabel 3 dapat dilihat rangka mengkonfirmasi apakah data bahwa disamping skor total employee well- empirik dilapangan sesuai dengan model being berhubungan positif dengan work konseptual yang diajukan oleh Zheng et engagement dan berhubungan negatif dengan perceived stress, setiap dimensi dari employee well-being juga menunjukkan korelasi positif dengan setiap dimensi work engagement. Setiap dimensi employee wellbeing juga berhubungan negatif dengan setiap dimensi dari perceived stress. Dimensi dari employee well-being adalah life well-being, workplace well-being dan psychological well-being. Dimensi dari work engagement adalah vigor, dedication dan absorption. Sedangkan dimensi dari perceived stress adalah perceived helplessness dan perceived inefficacy.

\section{Pembahasan}

Penelitian ini bertujuan untuk melakukan adaptasi pada alat ukur employee well-being dalam versi bahasa Indonesia yang belum pernah dilakukan sebelumnya di Indonesia. Untuk menguji validitas konstrak dilakukan dengan confirmatory factor analysis dalam al. (2015). Validitas konstrak diuji dengan menggunakan confirmatory analysis yang juga untuk memastikan uni dimensional alat ukur penelitian sesuai model yang diajukan oleh Zheng et al., (2015). Berdasarkan hasil confirmatory factor analysis, maka model yang fit ditunjukkan oleh telah tercapainya nilai-nilai goodness of fit pada penelitian ini. Setelah itu dapat dilihat nilai T yang mencapai nilai $>1,96$ yang menunjukkan relasi yang signifikan antara item dengan dimensinya dan dimensi dengan konstraknya, berdasarkan hasil perhitungan semua relasi item dengan dimensi dan dimensi dengan konstrak adalah signifikan. Selanjutnya maka perlu dilihat loading factor dari setiap item, untuk memastikan validitas dari alat ukur ini yang hasilnya $>0.5$. Berdasarkan kriteria-kriteria tersebut maka dapat dilihat validitas konstrak dari alat ukur ini tergolong baik.

Penelitian ini juga melihat convergent validity dengan mengkorelasikan employee 
well-being dengan work engagement. Selain itu discriminant validity dilakukan dengan mengkorelasikan employee well-being dengan perceived stress. Work Engagement dipilih karena dari hasil penelitian sebelumnya berhubungan positif dengan well-being (Ariza-Montes et al., 2019; Garg \& Singh, 2019; Joo \& Lee, 2017). Sebalinya, sebagai validitas diskriminan well-being berhubungan negatif dengan stress (Bell et al., 2012; Griffin \& Clarke, 2011; Mlangeni \& Van Dyk, 2017; Rahmi et al., 2021).

Alat ukur yang baik juga ditunjukkan oleh reliabilitas sebuah alat ukur. Penelitian ini menggunakan constract reliabilty. Dari hasil perhitungan constract reliability tergolong sangat baik, karena telah berada di atas 0.7 yaitu 0.942 , sehingga dapat diartikan bahwa alat ukur ini dapat diandalkan untuk mengukur employee well-being dalam sebuah penelitian.

\section{Kesimpulan}

Hasil penelitian menunjukkan bahwa Employee Well-Being Scale valid dan reliabel untuk dapat digunakan dalam pengukuran employee well-being pada sebuah penelitian. Hal ini terlihat dari terbuktinya properti psikometri dari EWBS sehingga adaptasi dari skala ini dapat dikatakan cukup baik. Untuk penelitian lebih lanjut, skala ini dapat diuji validitas konvergen dan diskriminannya menggunakan konstrak psikologi lainnya. Selain itu, alat ukur ini juga bisa diujicobakan pada subjek penelitian lainnya dengan core bisnis yang berbeda dengan tempat dilaksanakan penelitian ini.

\section{Datar Pustaka}

Ariza-Montes, A., Arjona-Fuentes, J. M., Han, H., \& Law, R. (2018). The price of success: A study on chefs' subjective well-being, job satisfaction, and human values. International Journal of Hospitality Management, 69, 84-93. https://doi.org/ 10.1016/j.jhm.2017.10.006

Ariza-Montes, A., Leal-Rodríguez, A. L., Ramírez-Sobrino, J., \& Molina-Sánchez, H. (2019). Safeguarding Health at the Workplace: AStudy of Work Engagement, Authenticity and Subjective Wellbeing among Religious Workers. International Journal of Environmental Research and Public Health, 16(17), 3016. https://doi. org/10.3390/ijerph16173016

Bell, A. S., Rajendran, D., \& Theiler, S. (2012). Job stress, wellbeing, work-life balance and work-life conflict among Australian academics. E-Journal of Applied Psychology, 8(1). https://doi.org/ 10.7790/ejap.v8i1.320

Bollen, K. A. (2014). Structural equations with latent variables. In Structural Equations with Latent Variables. John Wiley \& Sons, Inc. https://doi.org/10. 1002/9781118619179

Brey, P. (2012). Well-Being in philosophy, psychology, and economics. The Good Life in a Technological Age, 15-34. https://doi.org/10.4324/9780203124581

Ceja, L., \& Navarro, J. (2011). Dynamic patterns of flow in the workplace: Characterizing within-individual variability using a complexity science approach. Journal of Organizational Behavior, 32(4), 627651. https://doi.org/10.1002/job.747

Cohen, S. (1986). Contrasting the Hassles Scale and the Perceived Stress Scale. Who's Really Measuring Appraised Stress? American Psychologist, 41(6), 716-718. https://doi.org/10.1037/0003066X.41.6.716

Cotton, P., \& Hart, P. M. (2003). Occupational wellbeing and performance: A review of organisational health research. Australian Psychologist, 38(2), 118-127. https://doi. org/ 10.1080/00050060310001707117

Dagenais-Desmarais, V., \& Savoie, A. (2012). What is Psychological Well-Being, Really? A Grassroots Approach from 
the Organizational Sciences. Journal of Happiness Studies, 13(4), 659-684. https://doi.org/10.1007/s10902-0119285-3

Daniels, K. (2000). Measures of five aspects of affective well-being at work. Human Relations, 53(2), 275-294. https://doi. org/10.1177/a010564

Danna, K. (1999). Health and well-being in the workplace: a review and synthesis of the literature. Journal of Management, 25(3), 357-384. https://doi.org/10.1016/ S0149-2063(99)00006-9

Dimotakis, N., Scott, B. A., \& Koopman, J. (2011). An experience sampling investigation of workplace interactions, affective states, and employee wellbeing. Journal of Organizational Behavior, 32(4), 572-588. https://doi. org/10.1002/job.722

Garg, N., \& Singh, P. (2019). Work engagement as a mediator between subjective wellbeing and work-and-health outcomes. Management Research Review, 43(6), 735-752. https://doi.org/10.1108/MRR03-2019-0143

Griffin, M. A., \& Clarke, S. (2011). Stress and well-being at work. In APA handbook of industrial and organizational psychology, $\mathrm{Vol}$ 3: Maintaining, expanding, and contracting the organization. (pp. 359397). American Psychological Association.https://doi.org/10.1037/ 12171-010

Joo, B.-K., \& Lee, I. (2017). Workplace happiness: work engagement, career satisfaction, and subjective well-being. Evidence-Based HRM: A Global Forum for Empirical Scholarship, 5(2), 206-221. https://doi.org/10.1108/EBHRM-04-2015 $-0011$

Jöreskog, K. G. (1970). a General Method for Estimating a Linear Structural Equation System*. ETS Research Bulletin Series, 1970(2), i-41. https://doi.org/ 10.1002/ j.2333-8504.1970.tb00783.x

Kun, Á., Balogh, P., \& Krasz, K. G. (2016). Development of the Work-Related Well-Being Questionnaire Based on Seligman's PERMA Model. Periodica Polytechnica Social and Management Sciences, 25(1), 56 . https://doi. org/10.3311/PPso.9326

Leavitt, K., Fong, C. T., \& Greenwald, A. G. (2011). Asking about well-being gets you half an answer: Intra-individual processes of implicit and explicit job attitudes. Journal of Organizational Behavior, 32(4), 672-687. https://doi. org/10.1002/job.746

Mlangeni, N., \& Van Dyk, G. (2017). Reliability of measures of work engagement and psychological well-being among South African state security forces. Journal of Psychology in Africa, 27(4), 330-333. https://doi.org/10.1080/14330237.2017. 1347753

Page, K. M., \& Vella-Brodrick, D. A. (2009). The 'What', 'Why' and 'How' of Employee Well-Being: A New Model. Social Indicators Research, 90(3), 441-458. https://doi.org/10.1007/s11205-0089270-3

Rahmadani, V. G., Schaufeli, W. B., Ivanova, T. Y., \& Osin, E. N. (2019). Basic psychological need satisfaction mediates the relationship between engaging leadership and work engagement: A cross-national study. Human Resource Development Quarterly. https://doi. org/10.1002/hrdq.21366

Rahmi, T., Fitriana, E., Harding, D., \& Agustiani, H. (2021). Stress and Work Engagement: Meaningful Work as Mediator. Proceedings of the 2nd Progress in Social Science, Humanities and Education Research Symposium (PSSHERS 2020), 563. https://doi. org/10.2991/assehr.k.210618.069 
Saraswati, K. D. H. (2017). Perilaku Kerja, Perceived Stress, dan Social Support pada Mahasiswa Internship. Jurnal Muara IImu Sosial, Humaniora, Dan Seni, 1(1), 216. https://doi.org/10.24912/ jmishumsen.v1i1.352

Shier, M. L., \& Graham, J. R. (2011). Workrelated factors that impact social work practitioners' subjective well-being: Well-being in the workplace. Journal of Social Work, 11(4), 402-421. https://doi. org/10.1177/1468017310380486

Spector, P. E. (1997). Job satisfaction: Application, assessment, causes, and consequences. Sage.

Vandenberghe, C., Panaccio, A., Bentein, K., Mignonac, K., \& Roussel, P. (2011). Assessing longitudinal change of and dynamic relationships among role stressors, job attitudes, turnover intention, and well-being in neophyte newcomers. Journal of Organizational Behavior, 32(4), 652-671. https://doi. org/10.1002/job.732

Wright, T. A., \& Cropanzano, R. (1997). WellBeing, Satisfaction and Job Performance: Another Look At the Happy/Productive Worker Thesis. Academy of Management Proceedings, 1997(1), 364-368. https:// doi.org/10.5465/ambpp.1997.4988986

Wright, Thomas A., \& Cropanzano, R. (2004). The role of psychological well-being in job performance: A fresh look at an ageold quest. Organizational Dynamics, 33(4 SPEC.ISS.), 338-351. https://doi. org/10.1016/j.orgdyn.2004.09.002

Zheng, X., Zhu, W., Zhao, H., \& Zhang, C. (2015). Employee well-being in organizations: Theoretical model, scale development, and cross-cultural validation. Journal of Organizational Behavior, 36(5), 621-644. https://doi. org/10.1002/job.1990 